\title{
Entrevista com a Professora Micaela Ramon
}

\author{
Viviane Bagio Furtoso* \\ Ev’Ângela Batista R. de Barros**
}

Maria Micaela Dias Pereira Ramon Moreira é professora auxiliar do Departamento de Estudos Portugueses e Lusófonos do Instituto de Letras e Ciências Humanas da Universidade do Minho, onde leciona Literatura Portuguesa da época clássica e Português como Língua Estrangeira, em cursos de graduação, pós-graduação e extensão. É licenciada em ensino de PortuguêsFrancês, mestre em ensino da Língua e da Literatura Portuguesas e doutora em Literatura Portuguesa com uma tese intitulada A novela alegórica em português dos séculos XVII e XVIII: $o$ belo ao serviço do bem. É investigadora do Centro de Estudos Humanísticos da Universidade do Minho (Cehum), colaborando com o Centro Interuniversitário de Estudos Camonianos (Ciec) e o Centro de Literaturas de Expressão Portuguesa da Universidade de Lisboa (Clepul) em vários projetos. É diretora do Mestrado em Português Língua Não Materna e membro da direção do BabeliUM - Centro de Línguas da Universidade do Minho, com o pelouro do Português Língua Estrangeira. Tem publicadas as obras Os sonetos amorosos de Camões (1998), Sermão da Sexagésima e Sermões da Quaresma: Padre António Vieira

\footnotetext{
* Universidade Estadual de Londrina (UEL). Graduada em Letras Anglo-Portuguesas (1994) e Mestre em Letras (2001) pela UEL. Doutora em Estudos Linguísticos (2011) pela Unesp/São José do Rio Preto. Estágio pós-doutoral na Georgetown University, nos Estados Unidos (set. a dez./2015), com bolsa Capes/Fulbright. Professora adjunta do Departamento de Letras Estrangeiras Modernas da UEL. Atua nos programas de Pós-Graduação em Estudos da Linguagem (PPGEL) e Mestrado Profissional em Letras Estrangeiras Modernas (Meplem). Orcid: https:/orcid.org/0000-0001-6535-2902.

* Pontifícia Universidade Católica de Minas Gerais (PUC Minas). Mestre e doutora em Estudos Linguísticos (UFMG). Programa de Pós-Graduação e do Departamento de Letras da PUC Minas. Titular da Coordenação Setorial de Publicações e Produções Acadêmicas da Pró-Reitoria de Extensão. Editora gerente da Revista Conecte-se! da Proex PUC Minas. Editora da Revista do Instituto de Ciências Humanas da PUC, da Scripta e dos Cadernos Cespuc de Pesquisa. Orcid: https://orcid.org/00000001-8094-2329.
} 
(2017) e Obras pioneiras da cultura portuguesa, Primeira arte poética, Arte poética, ou regras da verdadeira poesia em geral, de Francisco José Freire (2019), sendo ainda autora de vários capítulos e artigos publicados em livros, revistas e atas de encontros, nacionais e internacionais, sobre temas ligados às áreas em que investiga e leciona.

Viviane e Ev’Ângela: Professora Micaela, a Língua Portuguesa (LP) está entre as 10 línguas mais faladas no mundo. Está presente em todos os continentes, e, curiosamente, não há dois países em que a língua portuguesa seja oficial que tenham fronteiras contíguas; assim, ela persiste como marca identitária. Como a Sr. ${ }^{\text {a }}$ avalia a situação mundial da LP, hoje?

Micaela Ramon: Penso que a situação atual da LP no mundo é francamente positiva. O português é uma língua que aparece muito bem posicionada, sejam quais forem os rankings considerados. Se tivermos em conta que há mais de sete mil línguas vivas no mundo e que, destas, apenas 94 têm mais de 10 milhões de falantes e, ainda, que o português integra esse grupo de idiomas, então, temos de ser otimistas quanto à nossa língua, a qual não parece sofrer qualquer ameaça de extinção num horizonte de tempo alargado. Para além disso, o facto de ser uma língua falada em todos os continentes garante-lhe um estatuto de língua global, assegurando-lhe presença ativa, não apenas nos países e regiões em que é língua oficial, mas também noutros territórios onde é levada pelas diásporas de todos os povos falantes de português e procurada como língua estrangeira.

Acresce ainda que as previsões de crescimento demográfico da maioria dos países de língua portuguesa, associadas à crescente 
taxa de escolarização dos povos dos Palop (Países Africanos de Língua Oficial Portuguesa) e de Timor, levam os especialistas a estimar que o número de falantes de português chegue aos 387.115 milhões, já em 2050, e possa ficar perto 500 milhões, no final do século. Estes são, portanto, motivos de entusiasmo em relação à projeção da língua portuguesa, os quais, por seu turno, trazem também grandes responsabilidades no que diz respeito às políticas de língua a desenvolver por todos os países da CPLP (Comunidade dos Países de Língua Portuguesa), dentro e fora das suas fronteiras.

Viviane e Ev'Ângela: Na sua perspectiva, a promoção e a difusão da LP por meio de instituições como a CPLP (Comunidade dos Países de Língua Portuguesa), o IILP (Instituto Internacional da Língua Portuguesa) e outros órgãos de gestão partilhada da língua têm conseguido atingir bons resultados?

Micaela Ramon: Sendo o português uma língua pluricêntrica, repartida por nove países com fronteiras geográficas descontínuas, mas unidos entre si pela mesma língua e por uma história partilhada, penso que faz todo o sentido a existência de instituições supranacionais de gestão, de difusão e de promoção da língua. Nesse sentido, organismos como a CPLP e o IILP são fundamentais. Desde logo porque, tratando-se de estruturas integradas por todos os países da comunidade falante do português e tendo dinâmicas de funcionamento que garantem a participação e a ocupação de lugares de direção por todos, acautelam a manutenção desse pluricentrismo da língua, assegurando o respeito pela sua diversidade sem, no entanto, lhe comprometer a unidade. 
Em termos concretos, os planos de ação, saídos das cimeiras da CPLP já realizadas (em Brasília, em Lisboa, em Díli), contêm linhas de orientação e declarações de princípio muito úteis para definir o rumo que a comunidade quer dar à gestão da língua e à articulação das ações a desenvolver por todos os membros integrantes, em áreas diversas, mas de interesse comum. Por seu lado, o IILP tem tido uma ação extremamente relevante no que diz respeito a políticas de definição do corpus da língua (por meio da elaboração do Vocabulário Ortográfico Comum do Português - VOC) e a políticas de ensino da língua, por meio do Portal do Professor de Português Língua Estrangeira - PPPLE, o qual, num esforço colaborativo e totalmente gratuito, tem disponibilizado a todos os interessados em adquirir ou aprofundar conhecimentos de português meios didáticos necessários para tal.

É claro que há ainda muito a fazer e que é necessário estimular o empenho contínuo de todos os países para dotarem esses organismos dos meios necessários à prossecução dos seus objetivos, garantindo, nomeadamente, que os contributos financeiros de todos os Estados membros não sejam desrespeitados ou interrompidos ao sabor das contingências das condições pontuais de cada país. Mas, nos seus princípios e fundamentos, reputo como muito importante a ação da CPLP e do IILP.

Viviane e Ev'Ângela: Faz diferença para a promoção da língua, em sua opinião, investir em ações gestadas nesse formato partilhado, se compararmos com ações unilaterais desenvolvidas pelos países da CPLP, mais especificamente, Brasil e Portugal? Comente, por favor. 
Micaela Ramon: A CPLP integra países com condições de desenvolvimento sócio-económico bastante desiguais. Até ao presente, os dois países que têm assumido maior destaque na definição e implementação de políticas de língua para o português são o Brasil e Portugal. O primeiro, através da Rede Brasil Cultural (RCB), presente em 44 países, e o segundo, por meio do Instituto Camões (IC), atuando em 85 países. A ação da RCB e do IC tem sido extremamente importante para promover a língua portuguesa como língua global e como língua internacional, pugnando pelo seu reconhecimento e pela sua utilização em organismos internacionais como a União Europeia, a União Africana, a Comunidade de Desenvolvimento da África Austral (SADC), a Comunidade Económica dos Estados da África Ocidental (Cedeao), entre outras; para além de terem um papel ativo no ensino do português pelo mundo e na promoção das culturas brasileira e portuguesa e do património (material e imaterial) a elas associado. Porém, seria desejável a existência de uma maior articulação entre essas duas redes que, por vezes e em certos contextos concretos, parecem funcionar mais como concorrentes do que como cooperantes para um propósito comum.

Por outro lado, e complementarmente, é altamente recomendável que os restantes países da CPLP possam desenvolver condições que os levem a ter um papel igualmente ativo no campo da promoção e divulgação do português, enquanto língua que também lhes pertence e para cuja vitalidade muito contribuem, garantindo-lhe precisamente o estatuto de língua global.

Só com uma maior equidade participativa se pode garantir que todos se sintam também representados e implicados e 


\section{Viviane Bagio Furtoso e Ev'Ângela Batista R. de Barros}

assumam como sua a tarefa de defesa, promoção e divulgação da língua portuguesa, não obliterando as circunstâncias específicas de uso em cada contexto, nomeadamente naqueles em que esse idioma partilha com outros o espaço que importa igualmente preservar e promover, numa lógica de ecologia linguística em que a diversidade não pode ser sinónimo de concorrência, mas antes de riqueza.

Viviane e Ev'Ângela: Em sua experiência como docente de Português Língua Estrangeira (PLE) em cursos de graduação, pós-graduação e extensão, quais os maiores desafios enfrentados?

Micaela Ramon: A minha experiência, quer como docente de PLE, quer como formadora de docentes/formadores para a área, tem sido extremamente gratificante. De facto, desde que, na última década do século passado, fui contratada como Assistente Estagiária para o Departamento de Estudos Portugueses da Universidade do Minho, sempre tenho trabalhado nesse campo, primeiro por necessidades de serviço, mas muito rapidamente por gosto e eleição própria, precisamente por ver aí uma oportunidade extremamente desafiante, tanto em termos de investigação, como de docência, como até mesmo de articulação entre a academia e a sociedade fora da universidade. De início, na minha universidade, os cursos de PLE eram apenas oferecidos no verão, como cursos de férias, e para públicos indiferenciados. À medida que a procura foi crescendo, surgiram novos desafios, não apenas relacionados com as tipologias dos cursos, mas também com a diversidade dos públicos-alvo. Assim, passamos a ter de dar resposta a necessidades diversificadas que nos levaram a criar cursos anuais e cursos semestrais (para além dos 
cursos de verão) e, dentro de cada tipologia, cursos também para fins específicos (PLE para fins académicos, para negócios, para áreas de atividade específicas, como enfermagem, engenharia, indústria do calçado, por exemplo), bem assim como para públicos para os quais o português tem diferentes estatutos: português língua segunda (PL2), português língua de herança (PLA), português língua estrangeira (PLE), etc. O apelo desses novos desafios foi tal, que, em 2009, foi criado o BabeliUM Centro de Línguas da Universidade do Minho, como forma de concretizar as políticas de multilinguismo definidas para essa instituição de ensino superior, cuja internacionalização crescente veio pedir novas estruturas para enfrentar os novos reptos em termos de políticas de língua.

Um outro desafio com que nos deparamos foi a necessidade de formar pessoas com competências específicas para atuar na área. Isso levou-nos a propor a criação do curso de Mestrado em Português Língua Não Materna - Português Língua Estrangeira/ Língua Segunda (PLNM - PLE/L2). De facto, se ainda hoje não é incomum encontrar pessoas sem qualificações de nível superior ou com qualificações desajustadas às necessidades específicas da área, o panorama que existia há 12 anos foi sem dúvida um estímulo para a criação de tal curso, como forma de dar resposta às lacunas existentes.

Viviane e Ev'Ângela: O Mestrado em Português Língua Não Materna (PLNM) da Universidade do Minho é um dos pioneiros em Portugal (ao lado de Lisboa, Porto e Coimbra). Quando começou a ser ofertado esse mestrado? Tem sido consistente a procura/o interesse por essa formação, na Universidade do Minho, desde então? Qual o perfil do público-alvo? 
Micaela Ramon: O MPLNM - PLE/L2 teve a sua primeira edição no ano académico de 2010-2011 e, desde então, tem tido uma procura constante, que se intensifica de ano para ano, acompanhando o interesse crescente que estudantes de todas as partes do mundo demonstram em relação ao português. Esse curso visa a dotar os alunos de ferramentas teóricas e práticas que lhes permitam intervir no campo da PLNM - PLE/ PL2, contribuindo para uma atualização e aprofundamento dos seus conhecimentos sobre a língua portuguesa e sobre as literaturas e culturas lusófonas e potencializando a aplicação de tais conhecimentos em diferentes contextos de investigação, de ensino ou de comunicação institucional e empresarial. $\mathrm{O}$ curso visa também a formar gestores capazes de operar em contextos exigentes e complexos de relações multilaterais, como investigadores e agentes de definição, implementação e avaliação de políticas linguísticas.

Esse mestrado foi projetado para responder às demandas do contexto global, fortemente marcado por mudanças significativas como resultado dos movimentos migratórios que têm contribuído para a diversidade sociocultural e linguística que caracteriza o mundo atual, globalizado e multilíngue. O MPLNM - PLE/ PL2 recruta o seu público-alvo não apenas entre os candidatos nacionais (licenciados pelas universidades portuguesas), mas também junto de estudantes estrangeiros provenientes, quer dos restantes países da CPLP, quer de outras instituições de ensino superior do mundo, com particular destaque para a China, para os países africanos com relações com outros países de língua oficial portuguesa (como o Senegal, a Costa do Marfim, ou a Tanzânia, por exemplo) e para os países europeus que integram a Rede Erasmus. Os candidatos são maioritariamente ou recém- 
licenciados em português e ciências humanas que pretendem iniciar uma carreira na área do PLE, ou pessoas que já atuam nesse domínio, mas que buscam adquirir ou atualizar conhecimentos específicos, numa lógica de formação contínua.

Viviane e Ev'Ângela: Como tem sido promovida a formação de professores de PLNM, em Portugal, considerando os diferentes contextos de aprendizagem de português (como língua de herança, língua de acolhimento, língua estrangeira, língua segunda, língua de ciência e outros)? Comente, de seu ponto de vista, aspectos que precisam ser considerados a partir dessa diversidade que o professor encontra ao longo de sua trajetória profissional.

Micaela Ramon: Os programas de formação de professores de PLNM têm-se vindo a adaptar aos diferentes contextos de uso da língua, nos quais ela adquire diferentes estatutos. No caso concreto do mestrado de que sou diretora, o plano curricular do curso procura proporcionar uma formação ampla e diversificada, tanto por meio da seleção de um conjunto de disciplinas obrigatórias cujos programas cobrem aspetos relacionados com as especificidades dos diferentes contextos de aprendizagem e uso do português, como também através da possibilidade dada aos estudantes de completarem a sua formação, selecionando disciplinas opcionais que melhor se adaptem aos seus interesses e necessidades.

Um aspeto importante a realçar é o facto de esse mestrado prever a realização de um estágio de prática supervisionada, o qual pode ser feito em instituições muito diversificadas, em Portugal e no estrangeiro, o que permite que os alunos, futuros 


\section{Viviane Bagio Furtoso e Ev'Ângela Batista R. de Barros}

professores, contactem com vários cenários, se familiarizem com eles e desenvolvam competências profissionais para neles atuarem, numa lógica de formação-ação-reflexão.

Do meu ponto de vista, no entanto, há duas áreas que apresentam maiores fragilidades: a do português como língua de acolhimento e a do português como língua de ciência. Nesses campos específicos, há ainda muito trabalho a realizar, quer ao nível da investigação, quer da aplicação prática dos conhecimentos obtidos através dos dados de análise. São, sem dúvida, áreas a explorar.

Viviane e Ev'Ângela: Prof. ${ }^{\text {a }}$ Micaela, a Sr. ${ }^{a}$ concorda que, apesar de estarmos acompanhando um avanço significativo na produção de conhecimento acumulado nos últimos anos acerca da elaboração de material didático para o ensino de PLE/PLNM, ainda observamos pouca presença da literatura, ou de gêneros literários, nesse recurso de acesso a informações linguísticoculturais pelos estudantes? Comente um pouco sobre como vê a elaboração de material didático e a relação com questões como a inserção da literatura e outros aspectos que merecem atenção por parte daqueles que se debruçam sobre a arte de elaborar material didático.

Micaela Ramon: Presentemente, há um crescente consenso relativamente ao facto de o texto literário (TL), como manifestação de língua autêntica, ser um instrumento particularmente útil para o desenvolvimento de competências multilíngues e multiculturais. Quer no plano da investigação teórica, quer das práticas concretas escoradas em abordagens metodológicas cada vez menos dogmáticas e mais abertas às 
reais necessidades dos diversos públicos-alvo, essa convição tem encontrado sustentação. Tratando-se de um tipo de texto que se caracteriza pela sua dimensão artística e cuja matéria-prima é uma língua natural, o TL adquire uma relevância inquestionável não apenas no plano linguístico, mas também no plano cultural, razão pela qual a sua utilização como recurso para o ensinoaprendizagem de línguas estrangeiras (LE) vem readquirindo um espaço que injustamente lhe havia sido sonegado, sobretudo a partir da segunda metade do século XX, quando as abordagens estruturalistas de forte pendor instrumental vieram lançar a suspeita de que tais tipologias textuais transmitiam uma visão artificial da língua e constituíam fator de discriminação e de afastamento de aprendentes de LE, supostamente incapazes de acederem à compreensão desse tipo particular de usos e de por eles se interessarem.

Quando está em causa uma língua como o português, caracterizada pelo seu pluricentrismo e consequente diversidade, a qual é a matéria-prima comum usada por uma vasta comunidade de escritores, oriundos de geografias dispersas e de contextos culturais heterogéneos, as mais-valias associadas ao conhecimento das diferentes literaturas criadas em língua portuguesa, para potenciar a aprendizagem do idioma como LE, ganham relevo, quer porque tais textos permitem dar a conhecer as suas variedades, quer porque estimulam o desenvolvimento do pensamento crítico e da criatividade, contribuindo para a formação de uma consciência intercultural dos estudantes e para o seu posicionamento como atores sociais.

Felizmente, a opinião que aqui partilho tem cada vez mais vozes a sustentá-la e tem, por isso, dado origem à criação de materiais pedagógicos muitíssimo interessantes e bem 


\section{Viviane Bagio Furtoso e Ev'Ângela Batista R. de Barros}

conseguidos que partem da exploração do TL como recurso para a aquisição de conhecimentos linguístico-culturais e o desenvolvimento de capacidades comunicativas (orais e escritas). Os exemplos são muitos, mas eu posso aqui citar, de entre outros que certamente existirão, os seguintes: Literaturas africanas de língua portuguesa I e II, de Silvie Spankova (editada em Brno, República Checa); Contos em português, de Rosa Bizarro e Lola Geraldes Xavier; Português com textos 1 e 2, de Sara Augusto e Caio César Christiano (ambos editados em Macau); ou a trilogia de Ana Viegas composta pelos títulos Era uma vez, Quem conta um conto, acrescenta um ponto e Vitória, vitória, acabou-se a história (editada em Portugal). Todos são excelentes exemplos de materiais didáticos que tomam por base o texto literário e que podem servir de estímulo e de modelo para a elaboração de outas propostas.

Viviane e Ev’Ângela: Chegando já ao final dessa ótima conversa, fale-nos um pouco sobre o que vem acompanhando e como entende o movimento de busca de equivalência entre os níveis dos exames do Caple e do Exame Celpe-Bras, bem como a criação de um sistema supranacional para certificação em PLNM além dos sistemas já existentes.

Micaela Ramon: Penso que seria muito útil para a afirmação do português como língua global, na sua unidade e diversidade, que as certificações feitas a partir dos dois exames de proficiência atualmente existentes, o Caple e o Celpe-Bras, fossem mutuamente reconhecidas e aceites como equivalentes. Estudantes estrangeiros de português perguntam-me muitas vezes por qual das variantes devem optar; simetricamente, 
também muitos futuros professores me questionam sobre qual delas devem ensinar. A minha resposta é sempre a mesma: devem ensinar aquela que melhor dominam (sem prejuízo de conhecerem, ou procurarem conhecer, as restantes, reconhecidas ou (ainda) não) e aquela que faz mais sentido para o públicoalvo, em função dos contextos de utilização.

A língua é só uma, a despeito da diversidade das suas variedades. Assim, penso que será um grande serviço prestado à promoção e difusão do português que, no campo da certificação como nos demais, as ações sejam desenvolvidas em cooperação e não em competição. Tal representará uma economia de recursos e de esforço e projetará certamente uma imagem de coesão que em muito beneficiará toda a comunidade lusófona, entendida em sentido amplo, ou seja, como o conjunto dos que falam a língua, seja como língua materna (L1), língua segunda (L2) ou língua estrangeira (LE).

Recebido em: 15/04/2021//Aceito em 22/04/2021. 